\title{
ASSOCIAÇĀO RARA: POLIMIOSITE, MIASTENIA GRAVE E TIMOMA
}

\author{
V. VAN BOEKEL*- J.M. GODOY**-J.M.T. MENEZES ***
}

\begin{abstract}
RESUMO - Fundamentados no fato de que, tanto na literatura naclonal quanto na estrangeira, inexiste referência da associaçäo de polimíosite, miastenia grave te timoma em adulto jovern do sexo masculino, os autores se propōem a descrever um caso aj citada síndrome. O paciente aqui apresentado teve sua doença iniciada aos 22 anos de idade, atingindo sua expressåo clinica máxima 4 anos majs tarda No estudo em apreço, são enfatizadas as dificuldades no diagnóstico diferencial entre polimiosite e miastenia grave, doencas que, a principlo, têm suas manifestacões clinicas caracteristicas, de mudo geral bem individualizadas. Na presente observacăo chamamos a atençao para a possivel $\epsilon$ xistência cle aspectos clínicos sugestivos de rilastenia em enfermos com polimlosite e, por cutro lado, alteracỏes histopatológlcas típicas de polimiosite em músculos de miastênicos, irviabilizando muitas vezes o diagnóstico clínico de certeza.
\end{abstract}

An unusual asnociation: polymyositis, myasthenia gravis, and thymoma.

SUMMARY - Eaged on the inexistence of references in Brazilian and International literature of the association polymyositis, myasthenia gravis and thymoma in a young male adult, the authors propase to describe one case presenting the associated syndrome. The disease began when the pattent was 22 years old, being the climax of its clinical expression four years later. It is emphasyzed the difficulty on the differential diagnosis between polymyositis and myasthenia gravis, once these diseases frequently have their clinical manifestations well individualized. In this study we call attention to the existence of clinical aspects of myasthenia gravis in patients presenting polymyositis and, on the other hand, histopathological alterations typical of polymyositis in myasthenic muscles, what makes the clinical diagnosis uncertain many times.

Polimiosite e miastenia grave são consideradas doenças «desimunes», provavelmente relacionadas a «discrasia linfocítica», termo utilizado por Engel et al.9. Existem, no momento, diversas evidências indicativas de semelhanças entre as duas enfermidades. Publicaçōes ocasionais têm descrito pacientes com aspectos clínicos e patológicos tanto de polimiosite quanto de miastenia, de forma concomitante 21. A situação complica-se ainda mais quando, em 1955, Stortebecker et al., citados por Paterson e ChurchillDavidson 20, descreveram alteraçōes histológicas em músculos de enfermos com miastenia grave aparentemente não complicada, alterações estas indistinguíveis daquelas observadas na polimiosite e doenças correlatas. Ambas parecem ter patogênese autoimune, ocorrendo com elevada freqüência em associação com outras de mesma natureza. Nas duas moléstias em questão, existe desequilíbrio de antígenos de histocompatibilidade: HLA B8 e HLA DR3, além de boa resposta ao uso de agentes imunos-

Unjdade de Terapia Intensiva do Hospital de Ipanema (HI, INAMPS-RJ): * Medicta do Serviço de Clínica Médica e da UTI do HI; * Profesasr Adjunto de Neurologia da Universidade do Estado do Rio de Janeiro (UERJ); ** Médica do Servico de Clínica Médica do $\mathbf{H I}$.

Dra. Valentina van Boekel - Rua Ozorto Duque Estrada 74/908B - 22451 - Rio de Janeiro RJ Brasil. 
supressores. Em ambas, o processo de autoagressão parece ser primariamente direcionado contra alguns componentes da musculatura esquelética 21 . Até o ano de 1978, foram publicados na literatura mundial 60 casos da associação polimiosite-miastenia grave 4. Tumor tímico foi descrito pela primeira vez por Cooper em 1832, citado por Souadjian et al.23. Estes estabeleceram correlação entre timoma e uma série de outras doenças, particularmente aquelas com características de autoimunidade, representadas com maior freqüência por: miastenia grave, citopenias incluindo aplasia pura de células vermelhas, neoplasias malignas, hipogamaglobulinemia e agamaglobulinemia, polimiosite e lúpus eritematoso sistêmico.

No relato de dois casos publicados por Klein et al.11, é enfatizada a íntima relação entre miastenia grave e polimiosite («inter alia» na presença de timoma) levando-se em conta o provável mecanismo autoimune comum, no qual a disfunção tímica exerce papel de destaque. Nesses dois casos, as manifestações miastênicas afloraram após realizaçăo de timectomia, sendo de conhecimento prévio a existência de timoma associado a manifestaçōes clínicas puras de polimiosite. Weiller et al.25, em levantamento bibliográfico encontraram 24 casos de associação de polimiosite, miastenia grave e timoma no periodo compreendido entre 1944 e 1981, a propósito da observação de um paciente com as mesmas patologias citadas, totalizando até o referido ano 25 casos. Os enfermos estudados eram predominantemente do sexo feminino, com média de idade de 56 anos. O diagnóstico, tanto de polimiosite quanto de miastenia, foi firmado pela história clínica, eletromiografia (EMG), biópsia muscular, enzimas musculares séricas, resposta a anticolinesterásicos e corticosteróides. O tipo histológico de timoma foi variável: 7 malignos, 11 benignos e 7 não determinados. Em cerca de $50 \%$ dos casos de polimiosite, foi observada a presença de células gigantes na histologia muscular. Em 15 dos 25 pacientes, foi identificada miocardite, que se manifestou de três formas: morte súbita, distúrbios do ritmo ou condução e insuficiência cardiaca severa de evoluçắo rápida.

A presente exposição tem por finalidade, pelo relato de caso clínico de jovem paciente com polimiosite, miastenia grave e timoma, confirmar e testemunhar o grande desafio enfrentado pelo médico na sua prática diária, quando da realização do diagnóstico diferencial entre duas moléstias tāo fascinantes.

\section{OBSERVAÇĀO}

IPF, 26 anos, masculino, branco, natural de $\mathrm{MG}$, auxiliar da escritório, solteiro, registro no HI 211807. A história teve início em janeiro-1984, após infecção de vias aéreas superiores, traduzida por fraqueza muscular de ambos os membros superiores, de predomínic proximal, sendo mais acertuada à direita (D), ocasionando dificuldade para barbear-se, pentear-se e sustentar objet.os acima do nivel da cabeça. Inexistiam, na ocasiāo, febre, artralgias, mialgias, fenômeno de Raynaud, alterações cutâneas ou perda ponderal. Havia, ¿m paralelo, registro de certa dificuldade para assoviar e sorrir. Evoluiu dessa forma até i início de maio do mesmo ano quando surgiu dor de moderada intensidade em região de ombro e braço $D$. Năo havia pađrão de flutuaçå diurna, relato de melhora com o r€pouso ou piora do sintoma pelo uso repetitivo dos grupos musculares envolvidos. Procurou assistência médica, sendo solicitado EMG, cujo resultado foi compativel a «distrofia fascioescapuloumeral». Fisioterapia foi indicada. A investigação não foi complementada com dosagem de enzimas musculares séricas e biopsic. muscular. A histórla familiar para miopatia era negativa. Cerca de 30 dias após, o paciente notou mudança do timbre vocal (caráter nasal), dificuldade para deglutir e levantar a cabeça do travesseiro, fraqueza muscular proximal nos niembros inferiores de caráter simétrico, caracterizada por prejuizo da deambulaçăo, dificuldade para subir escadas e episódios repetidos de queda da própria altura, associados a desconforto em ambas as panturrilhas. Piora paulatina dos sintomas culminou por justificar o confinamento do enfermo ao leito. Permaneceu dessa forma até junho-19s5 sem registro de remissões ou exacerbações cíclicas. Nessa épock, surgiu dispnéía de repouso que evoluiu em três dias para insuficiência respiratória secundária a apnéia. Nessa cocasiåo, estabelecemos o prímeiro contato com o paciente.

O exame clinico de entrada evidenciou total incapacidade para respirar espontaneamente, justificando o liso de prótese ventílatória (OHIOR-CCV2), permanecenđo em respiração controlada. Havia hipertermia de $38,50 \mathrm{C}$. A avaliação neurológica evidenciou diminuiçăo generalizada da força muscular, em especial do \&Trapezus», k\$sternocleldomastoldeus» e das cinturas escapular e pélvica. Observamos hipotonia generalizada associala a discreta atrofia dos músculos «I'ectoralis major» e «Deltoideus» à $D$. Devido à fresença de tubo oro-traqueal 
não foi possível avalfar a função muscular dos quadrantes inferiores da face, assim como dos territórios inervados pelos IX, $\mathbf{X}$ e XII nervos cranianos. A motricidado ocular o os demais tópicos do exame eram normais. Amostras de sangue foram colhidas para hemoculturas (6), hemcgrama, VHS, bioquímica (inclulndo perfil proteico), enzimas musculares, provas de atividade reumática (fator reumatóide, fator antinuclear, $\mathrm{C}_{8}, \mathrm{C}_{4} \mathrm{e} \mathrm{CH}_{50}$ ). $\mathrm{Havi}_{\mathbf{1}}$ discreta leucocitose neutrofflica, com elevaçảo da VHS (60mm na $1^{\text {q }}$ hora), aldolase=-12 U/L, $\mathrm{CPK}=140 \mathrm{U} / \mathrm{mL}, \quad A S T=100 \mathrm{U} / \mathrm{L}, \mathrm{ALT}=94 \mathrm{U} / \mathrm{L}$, A bioquímica c o EAS foram normais e as hemoculturas, urinocultura e provas de atividade reumática negativas. $O$ estudo radiográfico do tórax foi ncrmal e o eletrocardiograma acusou taquicardia sinustal. Biópsias musculares dos «Gastrocnemius»e «Deltoideus» à $D$ foram realizadas (registro 1303/85), que revelaram: focos esparsos de infiltrado intersticial mononuclear, do tipo linfoplasmocitário, com histiócitos de permeic, atingindo grupos de fibras necróticas (Fig. 1A), com basofilia cítoplasmática a regeneraçāo (Fig. 1B), núcleos centrais de cromatina granulosa e nucléolo proeminente; presença de infiltrado mononuclear perivascular (Fig. 1C), vasos de paredes espessadas e endotélio proeminente; compatível a polimiosite.

Diante da gravidade do caso apresentado, năo seria possível aguardar o resultado do laudo histopatológlco descrito. Na tentativa de descartar a hipótese de crise miastênica, o que nos parecia improvável, optamos pela ministraçăo intramuscular de neostigmina (1 mg). não sendo detectada qualquer melhora. Iniciamos pulsoterapia com metil-prednisolona (2g/dia) por três dias consecutivos, num total de dois ciclos com intervalo de uma semana. Após o primeiro, ocasiẫo em que foi realizada traqueostomia, já se percebia melhora da paresia da musculatura respiratória, sendo viável instituiçảo de respiraçảo assistida e posterior instalação de ventilaça mandatória intermitente, culminando com a retiradia da prótese respiratória sucedendo o segundo ciclo de pulsoterapia. Houve acentuada melhond do estado geral com desaparecimento da hipertermia, retorno da força muscular apendicular e resoluçāo da disfagia. Constatou-se, em paralelo, normalização dos níveis séricos das enzimas musculares e redução da VHS para $25 \mathrm{~mm}$ na $1^{\text {a }}$ hora. Iniciamos $60 \mathrm{mg}$ de prednisona/dia, sendo concedida alta hospitalar no $30 \%$ dia de internacão, permanecendo em acumpanhamento ambulatorial.

Em março-1986, inlciamos redução paulatina na dose de cortícosteróide (5 mg a cada 4 semanas), até que em novembro do mesmo ano, por ocasião da consulta ambulatorial, foram referidas as seguintes queixas: ptose palpebral à esquerda (E), que se acentuava quando da fixação da mirada vertical superior, e diplopia. $\mathrm{Na}$ epoca vinha em uso de 25 mg/dia de prednisona e o exame clinico-neurológico era inalterado, exceto pelos achados descritos. Os exames laboratoriais, inclusive VHS e enzimas musculares séricas, permaneciam dentro dos limites de normalidade. Procedemos, entāo, ao test s pelo cloreto de edrofônio que evidenciou pronunciada elevação da pálpebra. Associaçåo df brometo de piridostigmina (30 $\mathrm{mg}$ em 4 trmadas diárias) à prednisona determinou total cesaparecimento dos sinais e sintomas. Nảo foi possivel, no entanto, complementar a investigação diagnóstica do enfermo, pois perdemos contato com ele por motivos alheios à nossa vontade.

No final de outubro-1987, fomos novamente procurados pelo paciente com as seguintes queixas: recidiva de ptose palpebral (mais acentuada à $D$ ), diplopia, disfagia de transferência, timbre de voz nasal, dificuldade para sorrir e mastigar. Alegava ter interrompido o uso do anticolinesterásico há 5 meses, tendo-se instalado os sintomas e sinais mencionados em julho do mesmo ano. Contudo, persistiu durante todo o período fazenclo uso de prednisona na dose de $25 \mathrm{mg} /$ dia. o exame clínico era normal e, do porto de vista neurológico, os achados positivos eram: rima palpebral à $D$ com $0,8 \mathrm{~mm}$ e à $\mathbf{E}$ com $1,3 \mathrm{~mm}$, discreta paresia do músculo reto lateral à $D$, pobreza da mímica facial percebida sobretudo nos bucinadores e «Orbicularis oris», fraqueza muscular durante a manobra de oposição ao movimento de ambos masseteres, lentifiççāo durante a elevação do palato e đisfonia, força muscular comprometida, de igual maneira, nas provas dinâmicas dos músculos «Pectoralis major», «Deltoideus», «Biceps brachii», «Supraspinatus», «Infraspinatus», todos à D, concorrendo com leve amiotrofia e hjpotonia nos mesmos territorios. Foram colhidas nessa época (novembro-1987) amostras de sangue para avaliaçăo de enzimas musculares, imuneletroforese le proteinas,

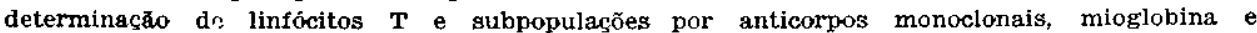
hemopexina e títulaçăo de anticorpos anti-receptor de acetilcolina (AC-AChr) t? antimúsculo esquelético. Todios os resultados encontravam-se dentro dos limites normais dé variação, com exceção dos seguintes: mioglobina=-resultado positivo, VHS $=25 \mathrm{~mm}$ na 17 hora, títulos de AC-AChr e antimúsculo esquelético foram, respectivamente, $163 \mathrm{nM} / \mathrm{L}$ e major ou igual a 180 U. Na nesma ocasião foi indicada EMG, cujos achados neurofisiológicos foram: (a) velocidades de condlção motora e sensitiva normais; (b) resposta muscular normal durante a estimulação nervosa repetitiva no músculo «Abdutor digiti mirimi» à D; (c) resposta de- 



Fig. 1 - Caso LPF. Aspectos histologicos da biopsia mus$\operatorname{cular}(A$, no alto; $B$, no meio; $C$, em baixo): descriç̃o no texto. 
crescente durante a estimulaçăo nervosa repetitiva no músculo «Orblcularis oculì à D (Fig. 2A) e normal após a ministracão intravenosa de $10 \mathrm{mg}$ de cloŕeto de edrofônio (Fig. 2B). (d) presença de ondas polif́́sicas (através de agulha concêntrica) de baixa voltagem nos músculos «Deltoideus», «Biceps brachii», «Extensor digitorum», «Abdutor policis brevis», «Tibialis anticus», e «Vastus medialis» à D e «Biceps», «Vastus medialis», «Gastrocnemius» $e$ «Tibialis anticus» à $\mathrm{E}$ (Fig. $2 \mathrm{C}$ e 2D).

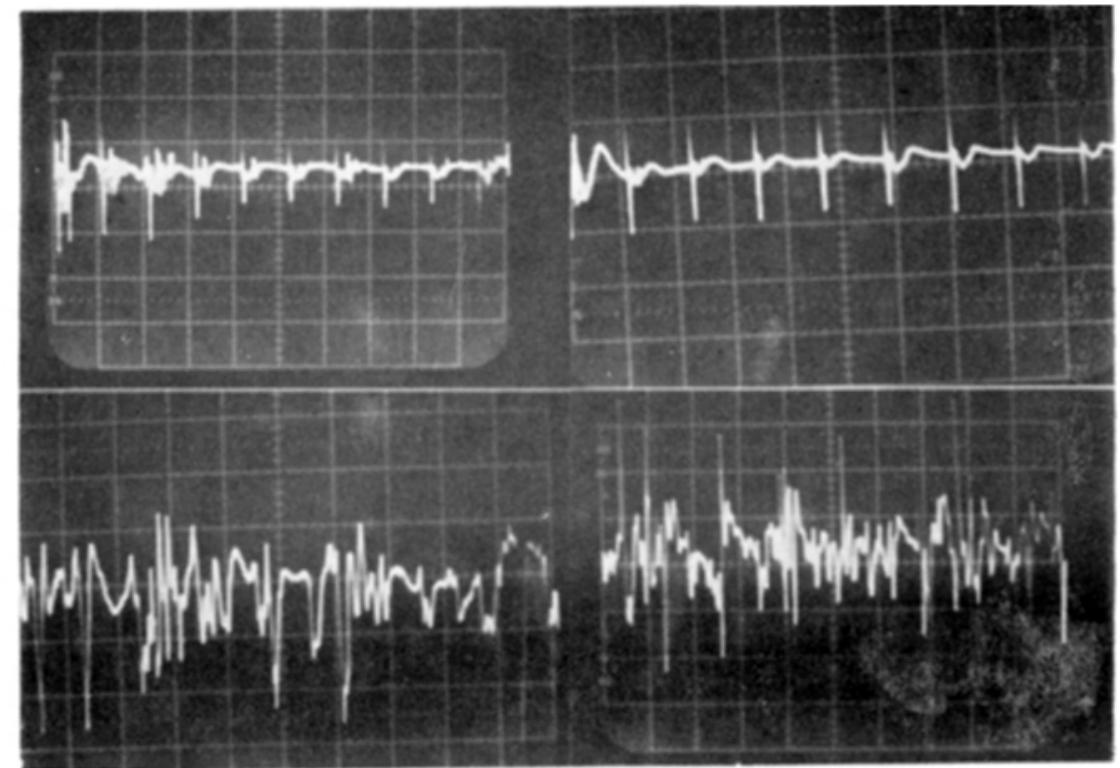

Fig. 2-Caso LPF. Exame eletromiográfico ( $A$, no alto à esquerda; $B$, no alto à direita; $C$, em baixo à esquerda; $D$, em baixo à direita): descrição no texto.

Após a ENiG reiniciamos brometo de piridostigmina na dose de $150 \mathrm{mg} /$ dia sasociado a prednisona, cuja dose fol elevada para $30 \mathrm{mg} /$ dia. No entanto, houve persistència de certo grau de disfagia e prejuizo da mastigaçâo. Em dezembro-1987, submetemos o paciente a cintilografia muscular com $99 \mathrm{~m}$ Tecnesio-pirofosfato que demonstrou distribuiçăo regular do material radioativo em ambos os membros inferiores, alêm de ausêncla de aumento de fixaçăo do radiotraçador em partes moles. A tomografia computadorizada (TC) do tórax acusou presença do timo, com espessura de cerca de $13 \mathrm{~mm}$ em seu lobo $\mathrm{E}$ e existêncis de calcificações em seu lobo D (Fig. 3A). Finalizamos a investigaçăo do caso cem a realizaçắo da uma segunda biópsia muscular («Deltoideus E») com estuđo histoquímico. O diagnostico foi de amiotrofia neurogênica, com a ressalva de que a presença de linforraglas e sacos nucleares segmentares seria sugeativa de miastenia grave. Cabe aqui sallentar que a histopatologia foi realizada na vigência de corticoterapia.

Diante de todos os dados relatados, indicamos realizaçăo de timectomia, cirurgla que transcorreu sem anormalidades e realizada através de esternotomia (Fig. $3 B$ ). $O$ exame anátomo-patológico foi conclusivo de timoma benigno de prədomináncia epitelıa! (Figs. 4A e 4B). Eirn janeiro-1988, efetuou-se nova avaliaçāo neurológica, que revelou discreta paresia do «Biceps brachii», «Supraspinatus», «Deltoideus», «Infraspinatus» e «Pectoralis major» a D, com atrofia concomitante de pequena monta e leve hipotonia. A musculatura inervada pelos nervos cranianos, assim como o restante do exame, não acuso: anormalidades. Complementamos o estudo do enfermo enviando amostras de seu sangue para o Instituto Lavoisler (Săo Paulo), com a finalidade de realização da tipagem dos antígenos de histocompetibilidade (HLA). Tal estudo, entretanto, não foi efetuado por dois motivos: (a) c número de células obtido năo foi suficiente para realizar o teste; (b) além disso, a viabilidade celular năo era adequada (em torno de 50\%). A análise fol repetida por duas vezes, não sendo obtido sucesso. Nenhuña explicação técnica nos fol dada para justiflcar a ocorrência de tal fenomeno.

No presente momento (outubro-1989), o enfermo apresenta-se sem qualquer queixa e com exame neurologico normal. Encontra-se em uso de prednisona (5 mg en dias alternados). 


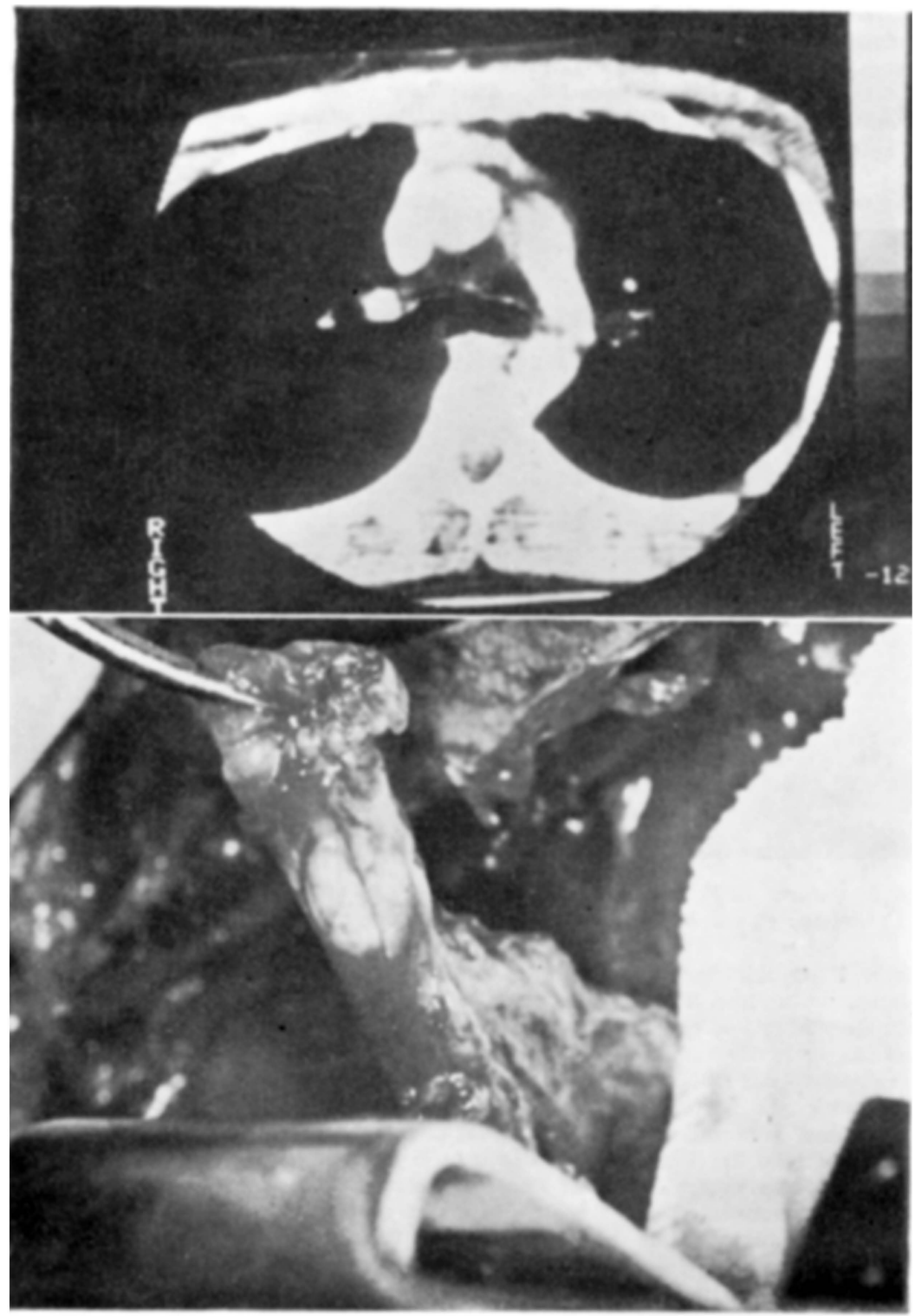

Fig. 3 - Caso LPF. Aspecto da tomografia computadorizada do tórax (A, no alto) e da timectomia ( $B$, em baixo): descrição no texto.

\section{COMENTARIOS}

Polimiosite apresenta-se, caracteristicamente, com fraqueza simétrica de cinturas escapular e pélvica, além de envolvimento freqüente da musculatura flexora cervical. Disfagia, dor e/ou sensibilidade muscular associadas a alterações cutâneas são comuns. Acometimento da musculatura respiratória também pode ser observado 13 . Inexiste critério absolutamente definido para o diagnóstico de polimiosite, a exemplo do que existe para doença reumática (critérios de Jones) e artrite reumatóide (critérios da Associação Americana de Reumatismo). Vez por outra, diagnóstico da doença em questão é estabelecido na ausência de elevação das enzimas musculares séricas, fato inclusive documentado por Marchiori et al.16, quando da análise de 63 pacientes 


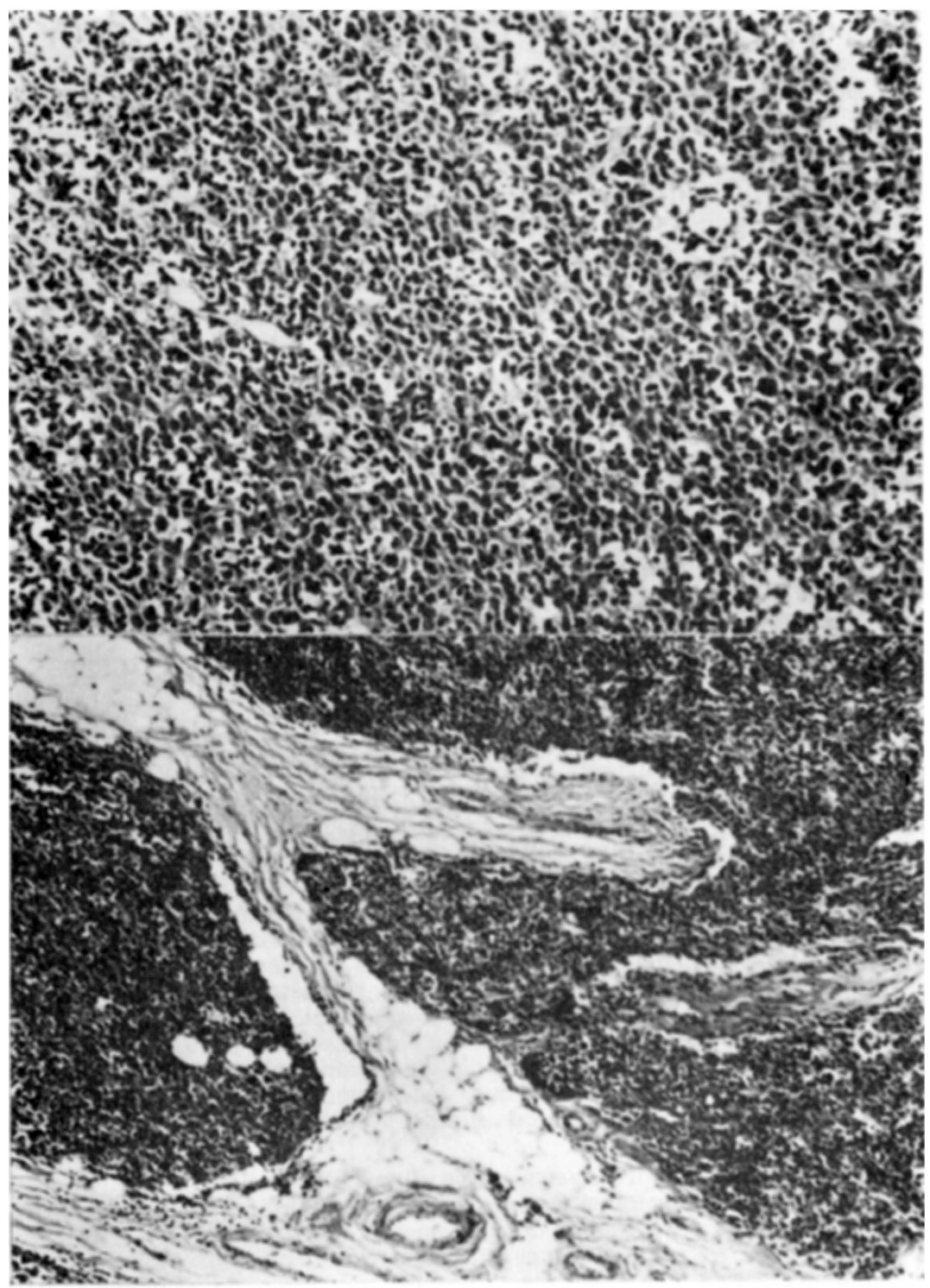

Eig. 4 - Caso LPF. Aspectos histologicos do timoma (A, no alto; $B$, em baixo): descricão no texto.

com dermatopolimiosite, dos quais 16 evoluiram com enzimas persistentemente normais, biópsias musculares ou EMG normais ou combinação dos elementos acima descritos. Existem, no entanto, 4 maiores critérios que nos auxiliam na definição do diagnóstico de polimiosite 5 , sendo eles: (a) padrão de fraqueza muscular típico; (b) EMG sugestiva; (c) biópsia muscular; (d) elevação de enzimas musculares séricas. $O$ diagnóstico definitivo de polimiosite é feito quando os 4 critérios estão presentes, provável quando da presença de três e possível em vigência de dois.

A moléstia em discussão, de forma ocasional, pode ser mais seletiva, mimetizando, por exemplo, a distrofia fascioescapuloumeral 13. Formas assimétricas de apresentação também são, ocasionalmente, reconhecidas 13. Existem ainda situaçōes em que dor e massa muscular inflamatória, caracterizando miosite focal, subseqüentemente 
evoluem para polimiosite generalizada 13. Fraqueza muscular de predomínio distal e oftalmoplegia são também descritas 5. Por essas afirmações, verificamos que o enfermo, objeto deste estudo, teve o diagnóstico de polimiosite feito com muito retardo, graças à apresentação inabitual da doença. Evidenciamos que a generalização do quadro teve início após 5 meses de evolução da enfermidade assumindo, então, padrão típico, culminando com insuficiência respiratória aguda. Diante de quadro clínico de extrema dramaticidade, achamos prudente a realizaçăo do teste da prostigmina, cujo resultado foi negativo. Contudo, é conhecida a ocorrência de respostas falso-positivas aos anticolinesterásicos na vigência de polimiosite $3,10,11,20$, dificultando algumas vezes o diagnóstico diferencial entre esta e a miastenia grave. Da mesma forma, resultados negatıvos com as mesmas drogas na miastenia não sâo mencionados na literatura. $\mathrm{O}$ que existe relatado sāo respostas de natureza variável ou pobre aos agonistas colinérgicos em situações como miastenia com miopatia tardia e miastenia com polimiosite tardia 10. Seguramente não era o caso do enfermo, pois inexistiam atrofias musculares clinicamente expressivas bem como paresia da musculatura extraocular em junho-1985.

É relatada a existência de timoma em associação tanto com polimiosite 20 quanto com miastenia grave. Por ocasião de tais associações, a resposta aos anticolinesterásicos e corticosteróides é pouco satisfatória, ao contrário do que foi evidenciado, pelo menos a princípio, no presente caso. Segundo Schwab e Perlo 22, a ocorrência de respostas falso-positivas com o cloreto de edrofônio e prostigmina poderiam ser explicadas em funçẫo da presença de músculos, nervos periféricos e neurônios motores lesados, o que propiciaria potencialização do efeito dos anticolinesterásicos em termos de contração muscular. De acordo com os mesmos autores, quando a droga foi investigada por Randall, pensava-se que ela atuaria diretamente em nivel de junção mioneural com efeito anticolinesterásico insignificante. Posteriormente, esta hipótese foi contestada, embora admita-se que o edrofônio possa ter açāo direta na contração muscular.

Outros dados na história que corroboraram o diagnóstico de polimiosite eram a existência de hipertermia e VHS elevada, pois foi afastada a concomitância de processo infeccioso por exame clinico, radiografia do tórax, hemograma, exame de urina, urinocultura e hemoculturas. Além disso, existia relato de dor e desconforto nos músculos do ombro e braço direitos, bem como em ambas as panturrilhas. Favorecendo o diagnóstico de polimiosite tinhamos os seguintes elementos: (a) padrāo clínico evolutivo da doença; (b) presença de febre e VHS elevada; (c) dor e desconforto musculares; (d) padrão eletromiográfico de miopatia (maio-1984); (e) teste farmacológico negativo; (f) biópsia muscular compatível a polimiosite; (g) elevação, apesar de discreta, das enzimas musculares séricas; (h) resposta exuberante ao corticosteróide. Após 16 meses de acompanhamento ambulatorial, com avaliaçōes laboratoriais seriadas normais, o enfermo apresentou queixas de fraqueza flutuante na musculatura extraocular, a despeito do uso de $25 \mathrm{mg} / \mathrm{dia}$ de prednisona. Com a positividade do teste pelo cloreto de edrofônio, estávamos em situação de difícil diagnóstico; tratar-se-ia de polimiosite de apresentação atipica?; polimiosite e miastenia grave concomitantes?

Quando do início da investigação mais detalhada, a VHS estava discretamente elevada, as enzimas musculares séricas persistiam normais, embora o nivel sérico de mioglobina, indicador especifico de destruição muscular, se mostrasse elevado. Askmark et al.2, pelo estudo de 85 pacientes com sintomas musculares, observaram níveis elevados de mioglobina sérica em $93 \%$ dos enfermos com miopatia miogênica, $54 \%$ com miastenia grave e em 50\% dos pacientes com miopatia neurogênica. Dentre os pacientes miastênicos estudados, niveis séricos elevados de mioglobina foram evidenciados nos casos de doença com maior severidade clinica (tipos llb, Ill e IV da classsificação de Osserman) e na vigência de elevadas titulações de $A C-A C h r$. No caso aqui descrito, o quadro clínico sugeria existência de miastenia óculo-oro-faríngea. Para nossa surpresa, o nivel sérico de hemopexina era normal pois, segundo Engel e Foidart-Dessalle 8 , esta glicoproteina pode ser considerada como índice de doença neuromuscular. Elevações de hemopexina foram demonstradas na distrofia muscular do tipo Duchenne, polimiosite-dermatomiosite e miastenia grave. É citada por Lisak e Zweiman 15 a possibilidade de detecção de uma série de anormalidades nos niveis de imunoglobulinas séricas na miastenia grave, polimiosite e dermatomiosite. Segundo os mesmos autores, casos isolados de gamapatia monoclonal foram descritos na miastenia grave e polimiosite, assim como hipogamaglobulinemia foi documentada em dois pacientes com timoma e miastenia grave. Com o objetivo de rastrear tais alterações, foi realizada imuneletroforese de proteinas séricas que se evidenciou normal no caso ora publicado. Objetivando confirmar os achados de Kornfeld et al.12, que 
postulam inexistência de prejuizo da imunidade celular em miastênicos timectomizados ou não, procedemos a determinação do estudo dos linfócitos $T$ e subpopulações por anticorpos monoclonais que não revelou anormalidades. Lisak e Zweiman 14 estendem tal afirmação em relação à polimiosite e dermatomiosite.

A EMG realizada em novembro-1987 mostrava padrão de extremo interesse. Como já tivemos oportunidade de relatar, o citado exame possibilitou registrar a presença de ondas polifásicas de baixa voltagem nos músculos apendiculares, enquanto a estimulação nervosa repetitiva demonstrou padrão miastênico. Constatamos, portanto, a existência de dois padrões eletromiográficos ou seja, um tipicamente miopático e outro característicamente miastênico, logo, a coexistência de polimiosite e miastenia grave. De acorđo com a classificação proposta por Johns et al.10, o enfermo pertenceria ao grupo «C». Neste último, as duas doenças podem coexistir por semanas, meses ou anos ou, ainda, os sintomas miastênicos predominam por semanas ou meses, sendo intermitentemente «substituídos» por aspectos clínicos de polimiosite, posteriomente pelos de miastenia e assim sucessivamente. Johns et al.10 tiveram oportunidade de acompanhar 14 pacientes com os citados aspectos, caracterizando a chamada polimiosite miastênica. Após realização da EMG, reinstituimos a medicação anticolinesterásica associada à prednisona. Ao contrário da excelente resposta obtida com a mesma medicação em novembro-1986, nesta ocasião observamos persistência de certo grau de disfagia e prejuízo da mastigação. Todavia, a ptose palpebral e a diplopia desapareceram por completo. Esse tipo de resposta nos fez pensar nas possibilidades que se seguem. (a) Interação adversa entre prednisona e piridostigmina, fato relatado por Engel 6 e Engel et al.7. Segundo eles, acentuada piora da fraqueza muscular foi observada com o uso associado das duas drogas. Esta hipótese nos pareceu improvável, pois essa mesma associação medicamentosa, em passado recente, resultou em melhora espetacular dos sintomas. (b) Resistência clínica à medicação anticolinesterásica, fenômeno documentado com freqüência 1. Esta hipótese também não nos pareceu atraente pois, apesar do paciente apresentar título sérico de AC-AChr expressivamente elevado, fez ele uso de medicação anticolinesterásica de forma contínua, por curto periodo e em baixas doses, não justificando alterações estruturais significativas em placa motora terminal. (c) Uma terceira hipótese obrigatória, mesmo levando em consideraçāo a pouca idade do enfermo, foi a possibilidade de coexistência de timoma, o que explicaria plenamente a pobre resposta à medicação. Outro dado que nos fez pensar em timoma foi a detecção de título sérico elevado de anticorpo antimúsculo esquelético 18.24. Segundo Papatestas et al.19, timoma representa estágio tardio de processo em que as manifestações precoces são hiperplasia e formação de folículos germinativos. Nada impediria, portanto, que a boa resposta observada, a princípio, aos anticolinesterásicos fosse justificada pela presença exclusiva de hiperplasia tímica. Com o passar do tempo, teria ocorrido transformação neoplásica do epitélio tímico anormal, com consequiente prejuízo da eficácia terapêutica.

Fundamentados em estudo realizado por Messina et al.17, indicamos realização de cintigrafia muscular com $99 \mathrm{~m}$ Tecnesio-pirofosfato. Nenhuma anormalidade no entanto foi detectada, seguramente em função do uso de corticosteróide, droga que já vinha sendo ministrada há 30 meses. Para confirmarmos a presença de timoma, realizamos TC do tórax, que acusou persistência tímica, tendo sido indicada timectomia.

Papatestas et al.19 estudaram 185 pacientes com miastenia grave no periodo compreendido entre 1941 e 1969: 111 aprésentavam miastenia não timomatosa e 74, miastenia com timoma. Todos foram submetidos a timectomia. Os autores concluíram que $50 \%$ dos enfermos que obtiveram remissão com timectomia atingiram tal estágio em dois ou mais anos, sendo o intervalo de tempo para o início de remissão dos sintomas diretamente relacionado com a atividade dos centros germinativos. $O$ porcentual de pacientes em remissão tendeu a aumentar com cada ano de pós-operatório consecutivo e $90 \%$ daqueles com 5 anos de seguimento encontravam-se em remissão ou com significativa melhora. Essa experimentação é consistente com a hipótese de que várias doenças de caráter autoimune sejam secundárias à proliferaçăo de clones anormais de linfócitos imunocompetentes em centros germinativos timicos. Alérn disso, os resultados obtidos sugerem que a timectomia determina ocorrência de remissão estável, pela eliminação das citadas estruturas. Entretanto, o efeito é tardio, pois a vida média desses pequenos linfócitos tende a ser longa 19.

Com base nos dados apresentados em nossa observação de 52 meses, concluímos que o caso em apreço assume conotação de extrema raridade, levando-se em consideração que, dentre os 25 casos publicados, somente 4 eram do sexo masculino e todos tinham mais de 50 anos de idade. Essas afirmações nos permitem considerar que seja o primeiro relato da síndrome com essas características na literatura. 


\section{REFERENCLAS}

1. Ashizawa 2: Elias SB, Appel SH - The interaction of myasthenic immunoglobulins and cholinergic agonists on acetylcholine receptors (AChrs) of rat myotubes. Neurology $30: 388,1980$.

2. Askmark H, Osterman PO, Roxin LE, Venge $\mathbf{P}$ - Radioimmunoassay of serum myoglobin in neuromuscular diseases. J Neurol Neurosurg Psychiat 44:68, 1981.

3. Barraquer-Ecrdas MML, Serra JP, Salisachs-Rowe $P$ - Polymyosite chronique nodulaire fcoale avec syndrome myasthénique. Rev Neurol 113:69, 1965.

1. Behan WMH, Behan PO, DICK HA - HLA-B8 in polymyositis. N Engl J Med 298:1260, 1978.

5. Bohan A, Feter JB - Polymyositis and dermatomyositis (first of two parts). N Engl J Med 292:344, 1975.

c. Engel WK - Myasthenia gravis, corticosteroids, anticholinesterases. Ann $N$ Acad Sci $274: 623,1976$.

7. Engel WK, Festoff BW, Patten BM, Swerdlow ML, Newhall HH, Thompson MD Myasthenia gravis. Ann Intern Med 81:225, 1974.

8. Engel WK, Foidart-Dessalle $\mathbf{M}$ - Elevations of hemopexin levels in neuromuscular disease. Arch Neurol 35:577, 1978.

9. Engel WK, Lichter AS, Dalakas MC - Splenic and total-body irradiation treatment of myasthenia gravis. Ann N Y Acad Sci 377:744, 1981.

10. Johns TR, Crowley WJ, Miller JQ, Campa JF - The syndrome of myasthenia and polymyositis with comments on therapy. Ann $N$ Y Acad Sci 183:64, 1971.

11. Klein JJ, Gottlieb AJ, Mones RJ, Appel SH, Osserman KE - Thymoma and polymyositis. Onset of nyasthenia gravis after thymectomy: report of two cases. Arch Intern Med 113:192, 1964.

12. Kornfeld F, Siegal S, Weiner LB, Osserman KE - Studies in myasthenia gravis: immunologic response in thymectomized and nonthymectomized patients. Ann Intern Med 63:416, 1965.

13. Lederman RJ, Salanga VD, Wilbourn AJ, Hanson MR, Dudley AW - Focal inflammatory myopathy. Muscle \& Nerve 7:142, 1984.

14. Lisak RP, Zweiman B - Mitogen and muscle extract induced in vitro prollferative responses in myasthenia gravis, dermatomyositis, and polymyositis. I Neural Neurosurg Psychiat 38:521, 1975.

15. Lisak RP, /4weiman B - Serum immunoglobulin levels in tryasthenia gravis, polymyositis, and dermatomyositis. J Neurol Neurosurg Psychiat $39: 34,1976$.

16. Marchiori PE. Hirata MTA, Scaff M, Oliveira RM, Cossermeli W, Levy JA, Assis JL Dermatopolimiosite: avaliação de 63 pacientes. Arq Neuro-Psiquiət (São Paulo) 45:137, 1987.

17. Messina C, Bonianno N, Baldare S, Vita G - Muscle uptake of muscular disorders: a $99 \mathrm{~m}$ technetium pyrophosphate in patients neuronquantitative study. J. Neurol Sci $53: 1,1982$.

18. Oosterhuis HJGH, Bethlem J, Feltkamp TEW - Muscle pathology, thymoma, and immunological abnormalities in patients with myasthenia gravis. $J$ Neurel Neurosurg Psychiat $31: 460,1968$.

19. Papatestas AE, Apert LI, Osserman KE, Osserman RS, Kark AE -- Studies in myasthenia gravis: effects of thymectomy results on 185 patients with nonthymornatous and thymomatous myasthenia gravis, 1941-1969. Am J Med 50:465, 1971.

20. Paterson JH, Churchlll-Davidson HC - Discussion on myasthenia. Proc Rey Soc Med $49: 789,1956$.

21. Pestronk A, Drachman DB - Polymyositis: reduction of acetylcholine receptors in skeletal muscle. Muscle \& Nerve 8:233, 1985.

22. Schwab RS, Perlo VP - Syndromes simulating myasthenia gravis. Aun $N$ Y Acad Sci $135: 350,1966$.

23. Souadjian JV, Enriquez P, Silverstein MN, Pépin JM - The spectrum of diseases associated with thymoma, coincidence or syndrome? Arch Intern Med 134:374, 1974.

21. Strauss AJL, Snell KC, Duntley BJ, Soban EJ, Stewart HL - Spontaneous thymuma, polymyositis, and serum autaantibodies to striated muscle in the rodent, subgenus Praomys (Mastomys) natalensis: similarities to thymoma with myasthenir gravis in man. Lancet $1: 1126,1968$.

25. Weiller PJ, Durand JM, Prince-Zucchelli MA, Cross D, Pouget J, Pelissier JF, Mongin M -- L'association polymyosite, myasthénie, thymome: un caș et revue de la litérature. Ann Med Interne 135:299, 1984. 